\title{
Assessing implicit alcohol associations with the implicit association test: fact or artifact?
}

Citation for published version (APA):

Houben, K. M. P. I., \& Wiers, R. W. H. J. (2006). Assessing implicit alcohol associations with the implicit association test: fact or artifact? Addictive Behaviors, 31, 1346-1362. https://doi.org/10.1016/j.addbeh.2005.10.009

Document status and date:

Published: 01/01/2006

DOI:

10.1016/j.addbeh.2005.10.009

Document Version:

Publisher's PDF, also known as Version of record

Document license:

Taverne

Please check the document version of this publication:

- A submitted manuscript is the version of the article upon submission and before peer-review. There can be important differences between the submitted version and the official published version of record.

People interested in the research are advised to contact the author for the final version of the publication, or visit the DOI to the publisher's website.

- The final author version and the galley proof are versions of the publication after peer review.

- The final published version features the final layout of the paper including the volume, issue and page numbers.

Link to publication

\footnotetext{
General rights rights.

- You may freely distribute the URL identifying the publication in the public portal. please follow below link for the End User Agreement:

www.umlib.nl/taverne-license

Take down policy

If you believe that this document breaches copyright please contact us at:

repository@maastrichtuniversity.nl

providing details and we will investigate your claim.
}

Copyright and moral rights for the publications made accessible in the public portal are retained by the authors and/or other copyright owners and it is a condition of accessing publications that users recognise and abide by the legal requirements associated with these

- Users may download and print one copy of any publication from the public portal for the purpose of private study or research.

- You may not further distribute the material or use it for any profit-making activity or commercial gain

If the publication is distributed under the terms of Article $25 \mathrm{fa}$ of the Dutch Copyright Act, indicated by the "Taverne" license above, 


\title{
Assessing implicit alcohol associations with the Implicit Association Test: Fact or artifact?
}

\author{
Katrijn Houben *, Reinout W. Wiers \\ Faculty of Psychology, Department of Experimental Psychology, Maastricht University, PO Box 616, \\ 6200 MD Maastricht, The Netherlands
}

\begin{abstract}
Studies using bipolar Implicit Association Tests (IATs) found that heavy drinkers have negative and arousal associations with alcohol relative to soda. Study 1 examined whether these results were due to the label 'alcohol' and the choice of the contrast category 'soda'. Four unipolar IATs assessed alcohol associations with positive and negative valence, arousal, and sedation, while varying the target dimension: alcohol or beer versus soda or animals. Results showed that drinkers had the strongest associations between alcohol and negative valence with the exact strength depending on the choice of the target categories. They also showed associations between alcohol and positive valence, arousal, and to a lesser extent sedation, which were uninfluenced by composition of the target dimension. These findings indicate ambivalence in both the valence and arousal-sedation dimension, underscoring the importance of using unipolar alcohol-IATs. Further, study 2 showed that "figure-ground" asymmetries could not account for these IAT results. These findings provide support that implicit alcohol associations are not merely IAT artifacts and that they can be assessed in a meaningful way with unipolar IATs.
\end{abstract}

(C) 2005 Elsevier Ltd. All rights reserved.

Keywords: Alcohol; Implicit Association Test; Implicit associations; Bipolarity; Figure-ground asymmetries

\section{Introduction}

The past decade, alcohol expectancies have been shown to be powerful predictors of drinking and it is now believed that they act as a common pathway for the influence of more distal risk factors for alcohol

\footnotetext{
* Corresponding author. Tel.: +31433881953; fax: +31433884196.

E-mail address: K.Houben@psychology.unimaas.nl (K. Houben).
} 
abuse (e.g., Goldman, 1999). Further, multidimensional scaling (MDS) research demonstrated that there are two basic dimensions underlying alcohol expectancies: a positive-negative and an arousal-sedation dimension. While expectancies in the arousal-sedation dimension have been found to discriminate between drinking levels, no relation has been found between expectancies in the valence dimension and drinking (e.g., Rather \& Goldman, 1994). This explanatory power of expectancy theory inspired researchers to develop a variety of expectancy measurement instruments that almost exclusively rely on self-report. Self-report measures, however, have been criticized because of their susceptibility to selfpresentation biases and the possibility that cognitive processes mediating alcohol abuse are not accessible through introspection (McCusker, 2001; Nisbett \& Wilson, 1977; Stacy, 1997). Therefore, alcohol research is now exploring the value of implicit measures, such as the now widely used Implicit Association Task (IAT; Greenwald, McGhee, \& Schwartz, 1998), that assess cognitions indirectly, without asking people to reflect and report on the motivations for their behavior.

The IAT is a double categorization task during which stimuli are classified into two times two categories with two response keys. Typically, two categories represent the target concepts (e.g., alcohol versus soda) and two categories correspond to the poles of an attribute dimension (e.g., positive versus negative). During the critical IAT trials, the target and attribute categories are assigned to two response keys in two different combinations. The assumption is that performance will be superior when associated concepts are assigned to the same response key (compatible combination), than when concepts sharing a response key are not or only weakly associated (incompatible combination). The performance difference between the two combination tasks, or the IAT effect, reflects the strength of implicit associations between the target and the attribute categories (Greenwald et al., 1998).

\subsection{Implicit alcohol associations}

Wiers, van Woerden, Smulders, and de Jong (2002) used the IAT to examine heavy and light drinkers' implicit alcohol associations with outcomes in both the arousal and valence expectancy dimension. Results showed that heavy drinkers, but not light drinkers, had implicit alcohol-arousal associations, paralleling results from MDS expectancy research. Surprisingly, and in contrast to MDS research, both light and heavy drinkers strongly associated alcohol with negative outcomes. These findings with the alcohol-IAT have been replicated in a sample of heavy drinkers (Wiers, van de Luitgaarden, van den Wildenberg, \& Smulders, 2005) and in a sample of patient drinkers (De Houwer, Crombez, Koster, \& De Beul, 2004). Wiers et al. (2002) linked the finding of implicit alcohol-arousal associations to the incentive-sensitization theory of addiction which states that addictive substances sensitize brain systems mediating processes responsible for motivating behavior and determining incentive salience ("wanting"), but not brain systems mediating the hedonic effects of addictive substances ("liking"). Once sensitized, this "wanting" system can be implicitly activated and automatically increases attention, arousal, and goal-directed behavior (Robinson \& Berridge, 1993, 2003). With respect to the finding of negative alcohol associations, three plausible explanations are available. First, Jones and McMahon (1996) argue that negative alcohol expectancies increase with consumption but without influencing drinking behavior until a certain threshold is reached. Second, implicit negative associations possibly reflect past, negative experiences whereas explicit cognitions may stem from more recent, positive experiences. Preliminary support for this account has already been obtained in relation to smoking (Rudman, 2004; Rudman \& Heppen, 2003). Third, the negative-alcohol IAT effect could be due to an artifact of the IAT procedure. 


\subsection{Methodological issues surrounding the IAT}

With respect to the IAT target dimension, there are two main problems. First, De Houwer (2001) argues that the IAT primarily measures associations at category level and that category labels determine IAT effects more strongly than exemplars (i.e., the 'label effect'). Additionally, IAT effects are prone to contamination by culturally shared associative knowledge (Karpinski \& Hilton, 2001; Olson \& Fazio, 2004). Hence, IAT results can be caused by cultural connotations carried by the category labels and superior IAT performance when alcohol and negative are mapped together could thus be due to negative cultural connotations of the label 'alcohol' . Second, the IAT is a relative measure: it compares the strength of implicit associations of one target category to those of the contrast category. As a result, faster performance when alcohol and negative (and soda and positive) are paired may be due to negative alcohol associations, positive soda associations or a combination of both.

Another problem with the IAT is that the attribute dimension is bipolar and that the test is therefore unfit for assessing ambivalent associations. This could be especially problematic when assessing implicit alcohol associations, since attitudes towards alcohol have been found to be highly ambivalent (Conner \& Sparks, 2002). Therefore, Jajodia and Earleywine (2003) modified the IAT by contrasting positive and negative categories with neutral ones. When attribute categories were tested in this unipolar format, performance was facilitated for both the combination of alcohol and positive words and the pairing of alcohol and negative words relative to the combination of mammals and neutral words. However, since the positive expectancy IAT was always performed before the negative expectancy IAT, order effects could have influenced results. It is a common finding that IAT effects are considerably larger the first time the task is performed and decrease with experience (Geenwald, Nosek, \& Banaji, 2003; Wiers et al., 2005).

Finally, IAT effects could reflect non-associative factors rather than implicit associations. Rothermund and Wentura (2004) proposed such a non-associative account of IAT effects that is based on salience. In a series of studies, they showed that salience or figure-ground asymmetries can produce IAT effects independent of implicit associations. When categories of an IAT dimension differ in salience, the salient category will act as figure against the less salient (back)ground category. Consequently, performing the IAT should be easier for consistent mappings of the figure categories of both IAT dimensions than when one figure and one ground category are assigned to the same response.

Two studies were designed that explored whether previous results with the alcohol-IAT could have been caused by these limitations. Study 1 examined the effect of using a contrast category other than soda on results with the alcohol-IAT as well as the effect of the label 'alcohol'. Also, the value of assessing implicit alcohol associations in a unipolar format was further explored. Study 2 examined whether the IAT results of study 1 could reflect salience asymmetries, instead of, or in addition to, implicit alcohol associations. To rule out such an alternative explanation, salience asymmetries between categories that formed an IAT dimension in study 1 were examined with visual search tasks which, according to Rothermund and Wentura (2004), can be used to objectively assess salience asymmetries.

\footnotetext{
${ }^{1}$ Public health campaigns in The Netherlands (and many other countries) typically stress the negative consequences of drinking alcohol whereas advertisements generally emphasize the positive and pleasant effects of drinking different brands of beer.
} 


\section{Study 1}

Four IAT versions were compared that differed with respect to the target dimension: alcohol vs. soda (cf. Wiers et al., 2002), alcohol vs. animals (cf. Jajodia \& Earleywine, 2003) ${ }^{2}$, beer vs. soda, or beer vs. animals. Further, the attribute categories positive, negative, arousal and sedation were tested against neutral attribute categories to examine the utility of unipolar alcohol-IATs. The IAT was expected to show both a strong negative attitude and a weak positive attitude towards alcohol whereas the opposite was expected for beer. ${ }^{1}$ Also, it was hypothesized that alcohol would be associated with arousal and that these associations would be related to alcohol use and problems, reflecting the activation of a sensitized "wanting" system. In addition, the relationship between these IAT effects and alcohol-related attitudes and expectancies was examined as well as the relation to recent and early alcohol-related experiences and social messages about alcohol use. IAT effects were expected to be related to both early alcohol experiences and social messages while self-reported attitudes and expectancies were expected to correlate with recent alcohol experiences.

\subsection{Method}

\subsubsection{Participants}

Ninety-six students of Maastricht University (48 males; mean age $=20.4$ years, $\mathrm{SD}=2.51$ ) participated in return for course credit or a gift certificate of 10. Participants at least occasionally drank alcohol, including beer with an average weekly alcohol consumption of $15.07(\mathrm{SD}=10.55)$ Dutch standard drinks. ${ }^{3}$ Participants had an mean score of $9.90(\mathrm{SD}=3.73)$ on the Alcohol Use Disorder Identification Test (AUDIT; Saunders, Aasland, Babor, De la Fuente, \& Grant, 1993), which is comparable to American college students (Fleming, Barry, \& MacDonald, 1991), and an average item score of .47 $(\mathrm{SD}=.33)$ on the 18 -items version of the Rutgers Alcohol Problem Index (RAPI; White \& Labouvie, 2000). The average item score in clinical samples is about .80 (White \& Labouvie, 1989).

\subsubsection{Materials and measures}

2.1.2.1. Alcohol use. Alcohol use was assessed with a self-report questionnaire based on the timeline follow-back method (Sobell \& Sobell, 1990). Participants were asked to indicate how many drinks of different types of alcoholic drinks they consumed on each day of the past week, and for each day of the week, how many drinks they typically consumed on this day.

2.1.2.2. Alcohol-related problems. Alcohol-related problems were assessed with the RAPI and the AUDIT. The RAPI described 18 alcohol-related problem situations and participants indicated how often they experienced these situations on a 5 -point Likert scale $(0=$ never, $4=$ often $)($ Cronbach $\alpha=.67)$. The AUDIT consisted of 10 multiple choice questions. The first three questions related to alcohol use, the other seven to alcohol-related problems $(\alpha=.76)$.

\footnotetext{
${ }^{2}$ Unlike in the study of Jajodia and Earleywine (2003), the animals category used here did not exclusively consist of positively evaluated mammals but instead of atypical animals, which were evaluated as neutral.

3 A standard alcoholic drink in Holland contains less alcohol than a standard English or American alcoholic drink: 10 vs. 14 g, respectively.
} 
2.1.2.3. Implicit alcohol associations. Participants performed either an alcohol-soda IAT, an alcoholanimals IAT, a beer-soda IAT or a beer-animals IAT. All (Dutch) target categories were matched on familiarity, valence, arousal and number of syllables. Each IAT version assessed associations in four evaluative dimensions: positive vs. neutral, negative vs. neutral, arousal vs. neutral, and sedation vs. neutral. The positive (label 'pleasant') and negative (label 'unpleasant') categories consisted of positive and negative nouns (cf. Greenwald et al., 1998) to assess general attitudes towards the target concepts. The arousal (label 'active' ${ }^{4}$ ) and sedation (label 'quiet' ${ }^{4}$ ) categories consisted of outcome expectancies (cf. Wiers et al., 2002) to assess associations with drinking outcomes. The (Dutch) positive, negative and their paired (in balanced order) neutral categories were matched on familiarity, arousal (neutral on arousal) and number of syllables. Likewise, the (Dutch) arousal, sedation and their paired (in balanced order) neutral categories were matched on familiarity, valence (neutral on valence) and number of syllables. All stimuli are presented in Appendix A. Internal consistencies, calculated as in Greenwald, Nosek, and Banaji (2003), were .46 for the positive dimension, .44 for the negative dimension, .52 for the arousal dimension, and .46 for the sedation dimension.

All IAT versions were programmed in ERTS 3.18 (Beringer, 1996) and consisted of seventeen blocks. Participants first received 24 trials of target discrimination practice using a right and a left response key. All target stimuli were presented twice. In the second block, the attribute classification (e.g., pleasant vs. neutral) was practiced with the same response keys. All attribute stimuli were presented twice. The third block was a combination block during which both target and attribute stimuli were presented twice for a total of 48 trials. Next, participants practiced the reversed attribute discrimination, followed by the reversed combination block. Blocks 2 to 5 were then repeated for the other three attribute dimensions. Stimuli were presented randomly with the restriction that targets and attributes were presented in alternating order (Greenwald et al., 1998). Stimuli appeared in the middle of the computer screen, in black against a grey background. Instructions were presented before each task. Category labels were presented in the upper corners of the computer screen in agreement with the required response and remained there during the task. Stimuli remained on screen until a response was given. Feedback ('wrong', 'too fast' [<300 ms] and 'too slow' [>3000 ms]) was presented in red beneath the stimuli. The intertrialinterval was $250 \mathrm{~ms}$.

2.1.2.4. Thought-listing. The thought-listing task (Rudman \& Heppen, 2003) asked participants to report five thoughts that came to mind quickly and easily about recent and early alcohol-related experiences and social messages about alcohol. Participants then indicated for each thought whether it was positive or negative on a 6 -point Likert scale $(-3=$ extremely negative, $+3=$ extremely positive $)$ They also rated the personal importance of all recent and early alcohol experiences on a 5-point Likert scale $(1=$ not at all important, $5=$ extremely important) and they estimated how often they encountered the social messages they listed on a 5 -point Likert scale $(1=$ seldom, $5=$ all the time $)$.

2.1.2.5. Explicit alcohol-related cognitions. Explicit alcohol-related cognitions were assessed with an expectancy questionnaire, an attitude questionnaire and a feeling thermometer. The alcohol

\footnotetext{
4 The labels 'active' and 'quiet' were chosen for the arousal and sedation category, respectively, because there are no suitable terms to denote 'arousal' and 'sedation' in Dutch.
} 
expectancy questionnaire consisted of 6 positive $(\alpha=.85), 6$ negative $(\alpha=.91), 7$ arousal $(\alpha=.65)$ and 7 sedation expectancy items $(\alpha=.65)$. Each item asked participants to indicate on a Visual Analogue Scale (VAS) how much they agreed or disagreed with the statement: "After drinking alcohol, I feel ...." For the positive and negative items, this statement was completed with the words unhappy, depressive, sad, lonely, moody, down, pleasant, happy, sociable, friendly, enjoyable, and likable. For the arousal and sedation statements, the same words as presented during the IAT were used, including the labels. The alcohol attitude questionnaire consisted of 4 semantic differentials which asked participants to indicate on a VAS how much they considered drinking alcohol to be unpleasant-pleasant, bad-good, boring-fun, and stupid-smart. The first and third item formed an affective attitude component $(\alpha=.90)$, the other two items formed a cognitive attitude component $(\alpha=.77)$. Finally, two feeling thermometers, labeled in $10^{\circ}$ increments ranging from 0 (cold) to 100 (warm), asked participants how favorable they felt about the target concepts (depending on condition: alcohol/beer and soda/animals).

\subsubsection{Procedure}

Participants first filled out an informed consent form. Next, they performed one of the four IAT versions. The response assignment of the target categories was balanced across participants. The presentation order of the attribute dimensions was partially balanced with a Latin square, resulting in 4 orders. Participants first performed the IAT with alcohol/beer paired with the relevant attribute category (positive, negative, arousal and sedation) and then with alcohol/beer paired with the neutral category. Participants then received the thought-listing questionnaire, the feeling thermometer, the alcohol attitude questionnaire and the alcohol expectancy questionnaire. These questionnaires referred to either alcohol or beer, depending on the IAT condition. Finally, participants received the alcohol use questionnaire, the AUDIT and the RAPI, and rated all IAT stimuli on familiarity, valence and arousal.

\section{Results}

\subsection{Implicit alcohol associations}

First, it was examined whether there were differences in reported alcohol use and problems between IAT conditions using 2 (target: alcohol or beer) $\times 2$ (contrast: soda or animals) univariate analyses of variance (ANOVA). Results showed no effect of target $(p>.25)$ or contrast $(p>.90)$ on reported alcohol use and a borderline significant effect of target $(p=.06)$ but no effect of contrast $(p>.90)$ on reported alcohol-related problems. ${ }^{5}$ Next, IAT effects were calculated with the new D600 algorithm (Greenwald et al., 2003) in such a way that higher IAT scores reflect a stronger association between alcohol/beer and positive, negative, arousal, or sedation. Then, the effect of target and contrast category on IAT effects for each evaluative dimension (positive, negative, arousal and sedation) was examined with a 2 (target:

\footnotetext{
5 There was a borderline significant trend that showed higher reporting of alcohol-related problems in the alcohol condition compared with the beer condition. Therefore, the factor target (alcohol vs. beer) was entered in the hierarchical regression analysis of alcohol problems in step 1 . Results showed that the pattern of results remained the same.
} 

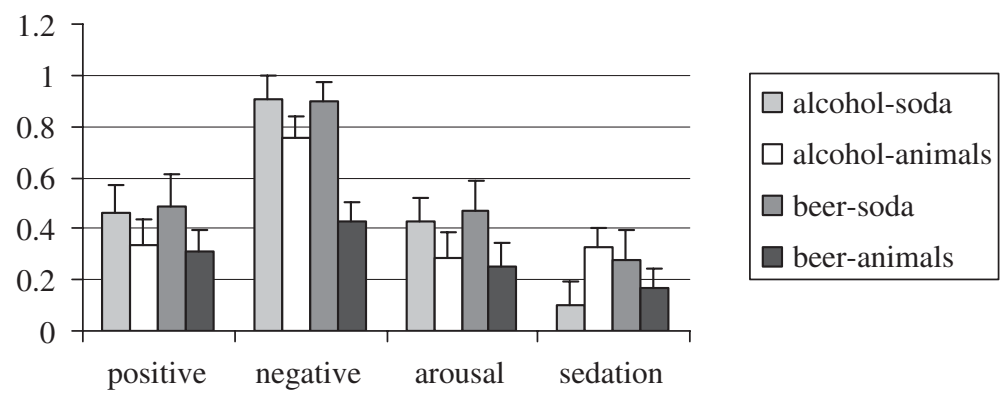

Fig. 1. Mean IAT effects (D600) separately for each evaluative IAT dimension and IAT version.

alcohol or beer) $\times 2$ (contrast: soda or animals) ANOVA. ${ }^{6}$ No significant effect of target was found for the positive, arousal and sedation dimension $(p>.90)$. For the positive and sedation dimension, the effect of contrast category was also not significant $(p>.15)$, while borderline significant for the arousal dimension, $F(1,91)=3.11, p=.081$. For the negative dimension, there was a significant effect of both target, $F(1,91)=4.28, p=.041$, and contrast category, $F(1,91)=14.14, p<.001$. The interaction between target and contrast category was borderline significant, $F(1,91)=3.76, p=.056$. In sum, the target label and the choice of the contrast category only influenced results for the negative IAT dimension.

For the positive, arousal and sedation dimension, the IAT effects were as follows (averaged across target and contrast categories): performance was faster when alcohol and positive words were assigned to the same response, $t(94)=7.67, p<.001(d=.78)$, when alcohol and arousal were mapped onto the same response, $t(94)=7.15, p<.001(d=.73)$, and when alcohol and sedation were paired, $t(94)=4.61$, $p<.001(d=.47)$ compared to when alcohol and neutral words shared a response. These findings demonstrate that drinkers hold strong implicit alcohol associations with positive valence, and with arousal and also to a lesser extent with sedation. For the negative evaluative dimension, planned comparisons between the four IAT versions showed that the IAT effect was significantly smaller in the beer-animals IAT than in both the beer-soda IAT, $t(46)=4.25, p<.001$ and the alcohol-animals IAT, $t(45)=3.01, p=.004$. No significant differences emerged between the alcohol-soda and the alcoholanimals IAT, $t(45)=1.23, p=.227$, nor between the alcohol-soda IAT and the beer-soda IAT, $t(46)=.087, p>.50$. These results show that the IAT effect was smaller in the beer-animals IAT than in the other IAT versions. Nevertheless, IAT performance was faster when alcohol and negative words shared a response than when alcohol and neutral words shared response in all four IAT versions: $t(23)=10.03, p<.001(d=2.05)$ for the alcohol-soda IAT, $t(22)=9.48, p<.001(d=1.98)$ for the alcohol-animals IAT, $t(23)=11.06, p<.001(d=2.26)$ for the beer-soda IAT and $t(23)=5.89, p<.001$ $(d=1.2)$ for the beer-animals IAT. These results indicate that drinkers strongly associate alcohol with negative valence and that the size of this implicit association is sensitive to the wording of both the target and contrast category. IAT effects for all evaluative dimensions per IAT version are shown in Fig. 1. Paired samples $t$-tests showed that IAT effects for the negative and the arousal dimension were significantly larger than IAT effects for the positive, $t(94)=5.41, p<.001$, and the sedation dimension, $t(94)=2.60, p=.011$, respectively.

\footnotetext{
${ }^{6}$ Preparatory analyses revealed the presence of an influential outlier who scored more than 4 standard deviations above the mean for the conventional measure on the arousal IAT dimension. This participant was excluded from the analyses. Outcomes were checked for the original sample including the outlier and results were generally the same.
} 


\subsection{Explicit alcohol-related cognitions}

Participants' mean score for positive and arousal alcohol expectancies significantly deviated from the neutral midpoint of the scale (55), $M=73.29, \mathrm{SD}=13.88, t(94)=12.84, p<.001 \quad(d=1.32)$, and $M=59.59, \mathrm{SD}=12.29, t(94)=3.63, p<.001 \quad(d=.37)$, respectively, indicating that they agreed with positive and arousal expectancies. Participants also significantly disagreed with negative and with sedation expectancy statements, $M=18.75, \mathrm{SD}=15.35, t(94)=-23.02, p<.001 \quad(d=2.36)$, and $M=41.32, \mathrm{SD}=13.62, t(94)=-9.79, p<.001(d=1.01)$, respectively. Analysis of mean scores on the VAS for both the affective and cognitive alcohol attitude component showed that participants had a positive attitude towards alcohol, $M=80.57, \mathrm{SD}=14.02, t(94)=14.65, p<.001 \quad(d=1.50)$, while knowing that drinking alcohol is unwise, $M=46.33, \mathrm{SD}=17.07, t(94)=-4.95, p<.001 \quad(d=.51)$. With respect to the feeling thermometers, paired samples $t$-tests showed that feelings towards animals $(M=77.92, \mathrm{SD}=15.05)$ were more favorable than feelings towards both alcohol $(M=66.88$, $\mathrm{SD}=14.79), t(23)=-2.14, p=.044$, and beer $(M=65.21, \quad \mathrm{SD}=16.38), t(23)=-3.31, p=.003$. Feelings towards soda $(M=65.32, \mathrm{SD}=14.23)$, in contrast, did not differ from feelings toward alcohol, $t(23)=-.19, p>.50$, or beer, $t(22)=.42, p>.50$. Before performing correlational analyses, all explicit measures and implicit D600 IAT scores were $z$-transformed per IAT condition (i.e. beer or alcohol vs. soda or animals). As can be seen in Table 2, IAT effects for both the positive and arousal dimension were significantly correlated with the affective attitude component and with feelings towards the target category, while a significant negative correlation emerged with feelings towards the contrast category. Also, IAT effects for both the positive and sedation dimension correlated positively with the cognitive attitude component. None of other correlations reached significance. ${ }^{7}$

\subsection{Alcohol use and related problems}

Estimates of alcohol consumption during the past week and of average weekly alcohol consumption were calculated from the alcohol use questionnaire. The weighed mean of these two $z$ transformed estimates and the $z$-transformed sum score of the first three AUDIT items was calculated as an estimate of mean alcohol use. Correlations between this alcohol use estimate and implicit and explicit measures are presented in Table 1. The alcohol use estimate correlated positively with the arousal IAT, with positive and arousal expectancies, with both the affective and cognitive attitude component and with feelings toward the target category. Alcohol use was also negatively correlated with negative expectancies. The alcohol use estimate was then entered into a hierarchical multiple regression analysis. All $z$-transformed explicit measures and implicit associations were entered in the first run of the regression analysis. All variables that did not predict $(p>.30)$ alcohol use were left out in the second run of the regression analysis. Results of the second run of the regression analysis for the prediction of alcohol use are shown in Table $2 .{ }^{7}$ In step 1, only gender was entered which significantly predicted alcohol use (men drink more than women). In step 2, the explicit arousal expectancies, affective attitude component and target feeling thermometer

\footnotetext{
${ }^{7}$ When the non-standardized explicit and implicit measures were used in the analysis, the pattern of results was generally the same.
} 
Table 1

Correlations between implicit and explicit measures, alcohol use and related problems

\begin{tabular}{|c|c|c|c|c|c|c|c|c|c|c|c|c|c|c|}
\hline & \multicolumn{4}{|l|}{ IAT } & \multicolumn{4}{|c|}{ Expectancies } & \multicolumn{2}{|l|}{ Attitude } & \multicolumn{2}{|l|}{ Feelings } & \multicolumn{2}{|l|}{ Alcohol } \\
\hline & Positive & Negative & Arousal & Sedation & Positive & Negative & Arousal & Sedation & Affective & Cognitive & Target & Contrast & Use & Problems \\
\hline \multicolumn{15}{|l|}{ IAT } \\
\hline Positive & - & & & & & & & & & & & & & \\
\hline Negative & .08 & - & & & & & & & & & & & & \\
\hline Arousal & $.30^{* *}$ & .14 & - & & & & & & & & & & & \\
\hline Sedation & $.32 * *$ & $.28 * *$ & $.36^{* *}$ & - & & & & & & & & & & \\
\hline \multicolumn{15}{|l|}{ Expectancies } \\
\hline Positive & .06 & -.08 & .16 & -.18 & - & & & & & & & & & \\
\hline Negative & -.02 & .13 & -.01 & .18 & $-.35^{* *}$ & - & & & & & & & & \\
\hline Arousal & .03 & .00 & .13 & -.04 & $.54 * *$ & -.11 & - & & & & & & & \\
\hline Sedation & .03 & .02 & -.06 & -.08 & .08 & $.36^{* *}$ & -.16 & - & & & & & & \\
\hline \multicolumn{15}{|l|}{ Attitude } \\
\hline Affective & $.29 * *$ & -.03 & $.24 *$ & .12 & $.50^{* *}$ & $-.28^{* *}$ & $.32 * *$ & .04 & - & & & & & \\
\hline Cognitive & $.25^{*}$ & .02 & .15 & $.22 *$ & .11 & -.16 & -.07 & .08 & $.49^{* *}$ & - & & & & \\
\hline \multicolumn{15}{|l|}{ Feelings } \\
\hline Target & $.38 * *$ & -.10 & $.29 * *$ & .12 & $.51 * *$ & $-.26^{*}$ & $.27 * *$ & .02 & $.70^{* *}$ & $.41 * *$ & - & & & \\
\hline Contrast & $-.28 * *$ & .05 & $-.23^{*}$ & -.12 & .08 & -.04 & .01 & .01 & -.09 & -.09 & -.06 & - & & \\
\hline \multicolumn{15}{|l|}{ Alcohol } \\
\hline Use & .12 & -.09 & $.29 * *$ & .10 & $.38^{* *}$ & $-.23 *$ & $.37 * *$ & -.03 & $.58^{* *}$ & $.23 *$ & $.52 * *$ & -.07 & - & \\
\hline Problems & .18 & .03 & $.26^{*}$ & $.31^{* *}$ & $.23^{*}$ & .06 & $.29 * *$ & -.03 & $.33 * *$ & .14 & $.27 * *$ & -.15 & $.60^{* *}$ & - \\
\hline
\end{tabular}

**Correlation is significant at the 0.01 level (2-tailed), *correlation is significant at the 0.05 level (2-tailed). All implicit and explicit measures were first $z$ transformed to control for confounding due to different task versions. ${ }^{5}$ 
Table 2

Summary of hierarchical regression analysis for explicit and implicit measures predicting alcohol use

\begin{tabular}{|c|c|c|c|c|c|c|}
\hline Variable & $B$ & SE $B$ & $\beta$ & $\operatorname{SE} \beta$ & $t$ & $\mathrm{p}$ \\
\hline \multicolumn{7}{|l|}{ Step 1} \\
\hline Gender & -.40 & .17 & -.24 & .10 & -2.43 & .017 \\
\hline \multicolumn{7}{|l|}{ Step 2} \\
\hline Gender & -.27 & .14 & -.16 & .08 & -1.94 & .056 \\
\hline Arousal expectancies & .18 & .07 & .22 & .09 & 2.52 & .013 \\
\hline Affective attitude & .28 & .10 & .33 & .12 & 2.81 & .006 \\
\hline Target feeling thermometer & .17 & .10 & .20 & .11 & 1.79 & .076 \\
\hline \multicolumn{7}{|l|}{ Step 3} \\
\hline Gender & -.26 & .14 & -.16 & .09 & -1.84 & .069 \\
\hline Arousal expectancies & .16 & .07 & .20 & .09 & 2.32 & .023 \\
\hline Affective attitude & .27 & .10 & .33 & .11 & 2.87 & .005 \\
\hline Target feeling thermometer & .19 & .10 & .22 & .12 & 1.91 & .060 \\
\hline Implicit positive associations & -.14 & .08 & -.16 & .09 & -1.81 & .073 \\
\hline Implicit arousal associations & .15 & .07 & .18 & .09 & 2.07 & .041 \\
\hline
\end{tabular}

were entered which significantly increased the variance explained. Both arousal expectancies and the affective attitude component significantly predicted alcohol use. In step 3, entering implicit positive and arousal associations significantly increased the variance explained. Implicit arousal associations significantly predicted alcohol use while implicit positive associations were borderline significant predictors.

An estimate of alcohol-related problems was computed as the weighed mean of the $z$-transformed RAPI sum score and the $z$-transformed sum score of the last seven AUDIT items. Because this estimate was not normally distributed, the RAPI and AUDIT sum scores were log-transformed before $z$ -

Table 3

Summary of hierarchical regression analysis for explicit and implicit measures predicting alcohol-related problems

\begin{tabular}{|c|c|c|c|c|c|c|}
\hline Variable & $B$ & SE $B$ & $\beta$ & $\mathrm{SE} \beta$ & $t$ & $\mathrm{p}$ \\
\hline \multicolumn{7}{|l|}{ Step 1} \\
\hline Gender & -.27 & .19 & -.15 & .10 & -1.48 & .142 \\
\hline \multicolumn{7}{|l|}{ Step 2} \\
\hline Gender & -.18 & .18 & -.10 & .10 & -1.01 & .315 \\
\hline Arousal expectancies & .20 & .09 & .22 & .10 & 2.19 & .031 \\
\hline Negative expectancies & .14 & .09 & .16 & .10 & 1.57 & .120 \\
\hline Affective attitude & .26 & .10 & .29 & .11 & 2.64 & .010 \\
\hline \multicolumn{7}{|l|}{ Step 3} \\
\hline Gender & -.17 & .17 & -.09 & .10 & -.95 & .345 \\
\hline Arousal expectancies & .22 & .09 & .24 & .10 & 2.44 & .016 \\
\hline Negative expectancies & .09 & .09 & .10 & .10 & 1.01 & .315 \\
\hline Affective attitude & .21 & .10 & .23 & .11 & 2.20 & .030 \\
\hline Implicit sedation associations & .24 & .09 & .26 & .10 & 2.73 & .008 \\
\hline
\end{tabular}

$F(1,93)=2.20, p=.142, R^{2}=.02$ for step $1 ; F_{\text {change }}(3,90)=5.91, p=.001, R_{\text {change }}^{2}=.16 ; F_{\text {change }}(1,89)=7.42, p=.008$, $R_{\text {change }}^{2}=.06$ for step 3. Final model $R^{2}=.25, R_{\text {adjusted }}^{2}=.20, F(5,94)=5.83, p<.001$. 
transformation. Correlations between the alcohol-related problems estimate and implicit and explicit measures are presented in Table 1. Alcohol-related problems correlated positively with arousal and sedation IAT scores, positive and arousal expectancies, the affective attitude component, and feelings toward the target category. The alcohol-related problems estimate was entered into a hierarchical multiple regression analysis, using the same procedure as described above. Results of the second run of the regression analysis for the prediction of alcohol-related problems are shown in Table $3 .^{7}$ In step 1, gender was entered which did not predict alcohol-related problems. In step 2, arousal and negative expectancies, and the affective attitude component were entered, which significantly increased the variance explained. Both arousal expectancies and the affective attitude component predicted alcoholrelated problems. Entering implicit sedation associations in step 3 significantly increased the variance explained.

\subsection{Thought-listing}

Indices were formed by multiplying valence scores of every recent and early thought with its assigned personal significance. For social messages, indexes were calculated by multiplying each message's valence with its frequency. Mean indices were then computed for recent experiences, earliest experiences and social messages. Recent experiences were more positive than both early experiences, $t(95)=5.50$, $p<.001$, and social messages, $t(95)=5.99$. No difference was found between the valence of early experiences and social messages, $t(95)=1.08, p=.283$. Correlations of $z$-transformed thought indices and implicit and explicit measures are presented in Table $4 .^{7}$ Recent and early alcohol experiences correlated positively with positive IAT scores, the two attitude components and feelings towards alcohol. Also, recent alcohol experiences correlated positively with positive expectancies and negatively with negative expectancies, whereas early alcohol experiences correlated positively with both arousal IAT scores and alcohol use. Unexpectedly, social messages correlated positively with both the cognitive attitude component and negative IAT scores.

Table 4

Correlations between reported thoughts and implicit and explicit measures

\begin{tabular}{lccc}
\hline & Recent experiences & Early experiences & Social messages \\
\hline Positive IAT & $.27^{* *}$ & $.33^{* *}$ & .02 \\
Negative IAT & .00 & -.15 & $.22^{*}$ \\
Arousal IAT & .14 & $.23^{*}$ & -.04 \\
Sedation IAT & .09 & .20 & .13 \\
Positive expectancies & $.34^{* *}$ & .18 & -.07 \\
Negative expectancies & $-.23^{*}$ & -.08 & -.10 \\
Arousal expectancies & .11 & .13 & -.05 \\
Sedation expectancies & .01 & .02 & .01 \\
Affective attitude & $.33^{* *}$ & $.39^{* *}$ & .07 \\
Cognitive attitude & $.22^{*}$ & $.24^{*}$ & $.24 *$ \\
Feelings target & $.36^{* *}$ & $.32^{* *}$ & -.03 \\
Feelings contrast & .09 & -.19 & $.23^{*}$ \\
Alcohol use & .16 & .19 & .14 \\
Alcohol problems & .08 & .08 & -.07 \\
\hline
\end{tabular}

$* *$ Correlation is significant at the 0.01 level $(2-$ tailed $), *$ correlation is significant at the 0.05 level (2-tailed). 


\section{Discussion}

The present results show that drinkers hold strong implicit associations between alcohol and negative valence $(d>1)$, with the exact size of this effect depending on the choice of the target categories (alcohol or beer vs. animals or sodas). Additionally, drinkers held significant (but weaker) associations between alcohol and positive valence, arousal, and to a lesser extent sedation, and these associations did not depend on the choice of the target categories. These findings indicate ambivalence in both the valence and the arousal-sedation dimension, underscoring the need to assess implicit alcohol associations in a unipolar format. Also, these results provide support that implicit alcohol associations are not merely IAT artifacts related to choice of the contrast target category and the target category labels. Nevertheless, the strong negative alcohol associations found in the IAT still contrast sharply with the scores on self-report measures. An alternative explanation for the present results is that the IAT reflects non-associative factors, instead of alcohol associations. This explanation is not implausible given that negative words typically act as figure (Rothermund \& Wentura, 2004) and that alcohol may be more salient in heavy drinkers (attentional bias).

\section{Study 2}

Study 2 assessed salience asymmetries between categories that formed an IAT dimension in study 1 with the visual search task. This task simultaneously presents four stimuli and participants have to decide if all stimuli belong to the same category or not. Since it takes longer to process salient stimuli than nonsalient stimuli, responses will be slower when the majority of stimuli (i.e., distractors) belong to the figure category than when they belong to the ground category (Rothermund \& Wentura, 2004). Hence, salience asymmetries are assessed by comparing performance when distractors belong to one category of an IAT dimension with performance when distractors belong to the other category of that dimension.

\subsection{Method}

\subsubsection{Participants}

A sample of 39 participants of study 1 ( 15 male; mean age $=20.5$ years, $S D=2.31)$, participated in return for course credit or a gift certificate of $7.5 €$.

\subsubsection{Materials and measures}

5.1.2.1. Visual search tasks. Participants performed eight visual search tasks, one for each IAT dimension presented in study 1 . Four visual search tasks assessed salience asymmetries between the target categories, the other four measured salience asymmetries between attribute categories. Visual search tasks were programmed in ERTS 3.18 (Beringer, 1996), following Rothermund and Wentura (2004). Before each visual search task, participants received 20 trials of a simple categorization task to practice the categorization of the stimuli. During these practice trials, each stimulus was presented twice. Participants were instructed to classify these stimuli with two response keys as quickly and as accurate as possible. After a wrong response, feedback was displayed beneath the stimulus ('ERROR - press correct key and continue') and the stimulus remained on the screen until the 
correct response was given. The intertrialinterval was $250 \mathrm{~ms}$. Next, the corresponding visual search task was performed. Each visual search task consisted of 12 practice and 64 test trials. During each trial, four stimuli were presented simultaneously. On half the trials, all four stimuli belonged to the same category ('same' trials), on the other half, three stimuli belonged to one category and the fourth (i.e., target) stimulus belonged to the other category ('different' trials). Participants indicated with two response keys whether all stimuli belonged to the same category or not. On half of the trials, distractors (three or four out of four stimuli) belonged to the first category of the respective dimension, on the other half of the trials, the distractors belonged to the second category. Stimuli were presented in the form of a square on half of the trials, and in the form of a diamond on the other half of the trials. During the different trials, the target appeared twice at each of the four possible locations. Each trial started with a ready signal (' $X$ ') displayed in the middle of the screen which was replaced by a cue ('*') when participants pressed the space bar. After $500 \mathrm{~ms}$, four stimuli were presented around the cue. Stimuli were always presented in black against a grey background. Instructions were presented before each visual search task. Response labels (same or different) were presented in the upper corners of the computer screen, in accordance with the response assignment and remained there for the duration of the task. Stimuli remained on screen until the correct response was given. In case of an error, feedback ('ERROR - press correct key and continue') was presented in red beneath the stimuli until the correct response was given.

\subsubsection{Procedure}

After filling out an informed consent form, participants performed all visual search tasks. The order of visual search tasks was partially balanced with a Latin square, resulting in 8 orders. The response assignment of same and different trials was balanced.

\section{Results and discussion}

Similar to Rothermund and Wentura (2004), trials with erroneous responses were left out of the analyses. For each visual search task, same and different trials were analyzed together, by computing mean reaction times for trials with distractors of the first category of the dimension (e.g., alcohol) and for trials with distractors of the other category (e.g., soda). No significant differences in responding were found between the target categories: $t(38)=1.67, p=.103$ for the alcohol-soda dimension, $t(38)=-.92, p=.363$ for the alcohol-animals dimension, $t(38)=-1.61, p=.115$ for the beer-soda dimension, and $t(38)=-1.28, p=.210$ for the beer-animals dimension. Thus, there was no evidence for salience asymmetries within the target dimensions. For the attribute dimensions, results indicated that responding to neutral distractors was significantly slower than responding to positive, $t(38)=-3.86, p<.001$, negative, $t(38)=-2.21, p=.033$, and sedation distractors, $t(38)=-2.87$, $p=.007$. No such effect was found for the arousal-neutral dimension, $t(38)=-.76, p=.452$. Hence, the neutral attribute categories appeared to be more salient than the positive, negative and sedation category. It should be noted, however, that the neutral stimuli possibly constituted a more heterogeneous sets than the positive, negative, arousal and sedation categories which could also have impaired performance during neutral trials. Nevertheless, no salience asymmetry was found for the arousal dimension. The present findings, consequently, imply that salience asymmetries cannot account for the IAT effects found in study 1. 


\section{General discussion}

The present research aimed at replicating and extending previous results with bipolar alcohol-IATs that showed that alcohol, relative to soda, is associated with both negative valence and arousal (De Houwer et al., 2004; Wiers et al., 2002, 2005). Here, negative alcohol associations were replicated with unipolar IATs that contrasted negative words with neutral words. Moreover, testing alcohol associations in a unipolar format also revealed positive alcohol associations, demonstrating that implicit alcohol associations are ambivalent. Further, as hypothesized, the labeling of the target category (alcohol or beer) and the choice of the contrast category (animals or sodas) influenced the strength of negative alcohol associations. Nevertheless, in all IAT versions, strong negative alcohol associations emerged, suggesting that they reflect something 'real' in the memory of drinkers rather than an IAT artifact. Possibly, negative implicit alcohol associations rise with alcohol use until some threshold is reached after which they begin to influence behavior (Jones \& McMahon, 1996). Here, however, no support was found for an increase in implicit negative alcohol associations with increased alcohol use. Alternatively, implicit negative alcohol-related cognitions could stem from early (negative) alcohol experiences and explicit positive alcohol-related cognitions from recent (positive) experiences. The present pattern of results, however, was not fully consistent with this hypothesis, implying that the distinction between implicit and explicit cognitions and their origins is not as clear-cut for alcohol as for smoking (cf. Rudman, 2004; Rudman \& Heppen, 2003). Hence, the question remains what these robust negative alcohol associations really mean. A remaining possibility is that they reflect negative reinforcement expectancies. Since targets and attributes alternate in the IAT, targets both precede and follow attributes. An observed association between alcohol and an attribute can therefore reflect both an association with an expected outcome (e.g., alcohol-positive: alcohol causes a positive mood) or with an antecedent mood state (e.g., positivealcohol: in a positive mood, drink alcohol).

Second, assessing alcohol associations in a unipolar format also revealed implicit alcohol associations with both arousal and sedation. Importantly, arousal associations predicted alcohol use while sedation associations predicted alcohol-related problems, above explicit measures. Further, implicit arousal associations were paralleled by explicit arousal expectancies and both were predictive of alcohol use. These results both replicate and extend previous findings (e.g., Wiers et al., 2002, 2005) and provide additional evidence for the development of arousal associations with drinking experience. The present results may reflect the operation of a "wanting" (sensitized arousal) system that becomes sensitized with repeated alcohol use and shows a progressive increase in the psychomotor activating response to alcohol (Robinson \& Berridge, 1993, 2003). Alcohol-related problems, on the other hand, were best predicted by implicit sedation associations, which could be related to research demonstrating that negative reinforcement motivations are strong predictors of alcohol-related problems (e.g., Cooper, Frone, Russell, \& Mudar, 1995). Together, these findings suggest that especially drinkers who consume alcohol to cope with negative affect are at risk of experiencing alcohol-related problems and developing a maladaptive drinking pattern.

A second study examined whether the present findings with unipolar IATs could be explained by figure-ground asymmetries. This was generally not the case, and certainly not for the alcohol-arousal associations. In sum, the present results underscore the usefulness of assessing alcohol associations in a unipolar fashion, support an explanation of implicit alcohol associations as meaningful memory constructs and refute artifact explanations in terms of target bipolarity, label effects and figure-ground effects. 


\subsection{Strengths and limitations of the IAT and issues for future research}

The IAT is useful for examining implicit associations but it does not come without limitations (cf. De Houwer, 2002). The present research showed that some of these limitations are not necessarily insuperable by demonstrating that the IAT, with minor revisions, can be used to assess ambivalent alcohol associations. However, it should be noted that the unipolar alcohol-IATs that were used here showed smaller internal consistencies than those reported for the bipolar alcohol-IAT (about .80; Wiers et al., 2005). Further, careful consideration should be given to the choice of the contrast target category. The present results show that contrasting alcohol with either soda or animals makes little difference. However, it should be noted that soda is a natural contrast to alcohol whereas the category animals are not. When a target category does not have a clear contrast (e.g., smoking), using such a neutral contrast may be useful, yet difficult (cf. Swanson, Rudman, \& Greenwald, 2001). This issue should be examined in future studies, but in the meantime, testing alternative association measures that do not require two contrasting target concepts could be a useful strategy (e.g., De Houwer, 2003; Nosek \& Banaji, 2001). Finally, using visual search tasks as a supplement to the IAT is recommended to examine confounding due to salience asymmetries.

In conclusion, implicit alcohol associations can be assessed in a meaningful way with unipolar IATs. This research strategy can be used in future studies on the role of implicit and explicit cognitions in the etiology and maintenance of alcohol abuse. Hopefully, further research on assessment issues of implicit alcohol-related cognitions will lead to a better understanding of automatic processes in addictive behaviors and their treatment.

\section{Acknowledgements}

Katrijn Houben and Reinout W. Wiers, Experimental Psychology, Faculty of Psychology, Maastricht University, The Netherlands. Both authors are funded by "VIDI" grant 452.02.005 from the Dutch National Science Foundation (N.W.O.) awarded to the second author. The authors wish to thank Fren Smulders for suggestions concerning the design of the study, Gerard van Breukelen for suggestions concerning the statistical analyses, and Remco Havermans for helpful comments on the manuscript. The data in this paper were presented as a poster, at the 27th Annual Meeting of the Research Society on Alcoholism, June 2004, in Vancouver, Canada.

\section{Appendix A}

\section{IAT target stimuli}

Alcohol: Wine, Bacardi, whisky, Heineken, Hoegaarden, Amstel (the last three are beer brands), Beer: Trappist, pint, Jupiler, Heineken, Hoegaarden, Amstel,

Soda: Spa (sparkling water), Fanta, Coca Cola, Sprite, apple juice, sinas (lemonade),

Animals: Cricket, duck, lizard, rhino, ostrich, hedgehog.

\section{IAT valence attribute stimuli}

Pleasant: Love, sunshine, warmth, peace, hug, rainbow, Unpleasant: War, depression, pain, fight, disease, sorrow, 
Neutral valence 1: Paper, circle, ballpoint, factory, truck, magnet,

Neutral valence 2: Letter, square, page, machine, scissors, window.

\section{IAT arousal/sedation attribute stimuli}

Active: Talkative, jovial, restless, alert, unrestrained, rambunctious, Quiet: Silent, listless, sleepy, passive, relaxed, calm,

Neutral arousal 1: Constant, wide, brown, digital, recent, usual, Neutral arousal 2: Oval, compact, related, central, daily, steep.

\section{References}

Beringer, J. (1996). Experimental run time system (ERTS) version 3.18. Frankfurt, Germany: BeriSoft.

Conner, M., \& Sparks, P. (2002). Ambivalence and attitudes. European Review of Social Psychology, 12, 37-70.

Cooper, M. L., Frone, M. R., Russell, M., \& Mudar, P. (1995). Drinking to regulate positive and negative emotions: A motivational model of alcohol use. Journal of Personality and Social Psychology, 69, 990-1005.

De Houwer, J. (2001). A structural and process analysis of the implicit association test. Journal of Experimental Social Psychology, 37, 443-451.

De Houwer, J. (2002). The implicit association test as a tool for studying dysfunctional associations in psychopathology: Strengths and limitations. Behavior Therapy and Experimental Psychiatry, 53, 115-133.

De Houwer, J. (2003). The extrinsic affective Simon task. Experimental Psychology, 50, 77-85.

De Houwer, J., Crombez, G., Koster, E. H. W., \& De Beul, N. (2004). Implicit alcohol-related cognitions in a clinical sample of heavy drinkers. Journal of Behavior Therapy and Experimental Psychiatry, 35, 275-286.

Fleming, M. F., Barry, K. L., \& MacDonald, R. (1991). The alcohol use disorders identification test (AUDIT) in a college sample. The International Journal of the Addictions, 26, 1173-1185.

Goldman, M. S. (1999). Risk for substance abuse: Memory as a common etiological pathway. Psychological Science, 10, $196-198$.

Greenwald, A. G., McGhee, D. E., \& Schwartz, J. L. K. (1998). Measuring individual differences in implicit cognition: The implicit association test. Journal of Personality and Social Psychology, 74, 1464-1480.

Greenwald, A. G., Nosek, B. A., \& Banaji, M. R. (2003). Understanding and using the implicit association test: 1. An improved scoring algorithm. Journal of Personality and Social Psychology, 85, 197-216.

Jajodia, A., \& Earleywine, M. (2003). Measuring alcohol expectancies with the implicit association test. Psychology of Addictive Behaviors, 17, 126-133.

Jones, B. T., \& McMahon, J. (1996). A comparison of positive and negative alcohol expectancy and value and their multiplicative composite as predictors of post-treatment abstinence survivorship. Addiction, 91, 89-99.

Karpinski, A., \& Hilton, J. L. (2001). Attitudes and the implicit association test. Journal of Personality and Social Psychology, $81,774-788$.

McCusker, C. G. (2001). Cognitive biases and addiction: An evolution in theory and method. Addiction, 96, 47-56.

Nisbett, R. E., \& Wilson, T. D. (1977). Telling more than we can know: Verbal reports on mental processes. Psychological Review, 84, 231-259.

Nosek, B. A., \& Banaji, M. R. (2001). The Go/No-Go association task. Social Cognition, 19, $625-664$.

Olson, M. A., \& Fazio, R. H. (2004). Reducing the influence of extra-personal associations on the implicit association test: Personalizing the IAT. Journal of Personality and Social Psychology, 86, 653-667.

Rather, B. C., \& Goldman, M. S. (1994). Drinking-related differences in the memory organization of alcohol expectancies. Experimental and Clinical Psychopharmacology, 2, 167-183.

Robinson, T. E., \& Berridge, K. C. (1993). The neural basis of drug craving: An incentive-sensitization theory of addiction. Brain Research Reviews, 18, 247-291.

Robinson, T. E., \& Berridge, K. C. (2003). Addiction. Annual Review of Psychology, 54, $25-53$. 
Rothermund, K., \& Wentura, D. (2004). Underlying processes in the implicit association test: Dissociating salience from associations. Journal of Experimental Psychology. General, 133, 139-165.

Rudman, L. A. (2004). Sources of implicit attitudes. Current Directions in Psychological Science, 13, $79-82$.

Rudman, L. A., \& Heppen, J. B. (2003). Sources of implicit attitudes toward smoking (unpublished manuscript).

Saunders, J. B., Aasland, O. G., Babor, T. F., De la Fuente, J. R., \& Grant, M. (1993). Development of the alcohol use disorders identification test (AUDIT): WHO collaborative project on early detection of persons with harmful alcohol consumption. Addiction, 88, 791-804.

Sobell, L. C., \& Sobell, M. B. (1990). Self-report issues in alcohol abuse: State of the art and future directions. Behavioral Assessment, 12, 77-90.

Stacy, A. W. (1997). Memory activation and expectancy as prospective predictors of alcohol and marijuana use. Journal of Abnormal Psychology, 106, 61-73.

Swanson, J. E., Rudman, L. A., \& Greenwald, A. G. (2001). Using the implicit association test to investigate attitude-behaviour consistency for stigmatised behaviour. Cognition and Emotion, 15, 207-230.

White, H. R., \& Labouvie, E. W. (1989). Towards the assessment of adolescent problem drinking. Journal of Studies on Alcohol, 50, 30-37.

White, H. R. \& Labouvie, E. W. (2000). Longitudinal trends in problem drinking as measured by the Rutgers Alcohol Problem Index. Paper presented at the 23rd Annual Scientific Meeting of the Research Society on Alcoholism, Denver, CO.

Wiers, R. W., van de Luitgaarden, J., van den Wildenberg, E., \& Smulders, F. T. Y. (2005). Challenging implicit and explicit alcohol-related cognitions in young heavy drinkers. Addiction, 100, 806-819.

Wiers, R. W., van Woerden, N., Smulders, F. T. Y., \& de Jong, P. J. (2002). Implicit and explicit alcohol-related cognitions in heavy and light drinkers. Journal of Abnormal Psychology, 111, 648-658. 